\title{
Racial disparities in total ankle arthroplasty utilization and outcomes
}

Jasvinder A Singh ${ }^{1,2,3^{*}}$ and Rekha Ramachandran ${ }^{2}$

\begin{abstract}
Introduction: The objective of this study was to examine the racial disparities in total ankle arthroplasty (TAA) utilization and outcomes.

Methods: We used the National Inpatient Sample (NIS) to study the time-trends. Race was categorized as White and Black. Utilization rates were calculated for the U.S. general population per 100,000. Hospital length of stay, discharge disposition and mortality after TAA were assessed. We used the Cochran Armitage trend test to assess time-trends from 1998 to 2011 and chi-square test to compare TAA utilization. We used analysis of variance or chi-squared test to compare the characteristics of Whites and Blacks undergoing TAA and logistic regression to compare mortality, length of stay and discharge to home versus medical facility.
\end{abstract}

Results: The mean ages for Whites undergoing TAA were 62 years and for Blacks was 52 years. Significant racial disparities were noted in TAA utilization rates $(/ 100,000)$ in $1998,0.14$ in Whites vs. 0.07 in Blacks $(P<0.0001$; 2-fold) and in 2011, 1.17 in Whites vs. 0.33 in Blacks $(P<0.0001$; 4 -fold). Racial disparities in TAA utilization increased significantly from 1998 to $2011(P<0.0001)$. There was a trend towards statistical significance for the difference in the length of hospital stay in Blacks vs. Whites (52.9\% vs. $44.3 \%$ with length of hospital stay higher than the median; $P=0.08)$.

Differences in the proportion discharged to an inpatient medical facility after TAA, 16.6\% Blacks vs. 13.4\% Whites, were not significant $(P=0.36)$.

Conclusions: This study demonstrated significant racial disparities with lower TAA utilization and suboptimal outcomes in Blacks compared to Whites. Further studies are needed to understand the mediators of these disparities and to assess whether these mediators can be targeted to reduce racial disparities in TAA.

\section{Introduction}

Racial and ethnic disparities are widespread in health care [1-5]. The 2002 Institute of Medicine report called for 'Confronting Racial and Ethnic Disparities in Health Care' [6]. The 2009 Institute of Medicine's comparative effectiveness research agenda included reduction in racial disparities in the first quartile of the 100 top priority areas [7]. Unless all segments of the population receive optimal health care, best health care outcomes cannot be realized for the population as a whole. Racial disparities in arthroplasty are of great interest, due to several reasons. Lower

\footnotetext{
* Correspondence: jassingh@uab.edu

'Medicine Service, Birmingham VA Medical Center, Faculty Office Tower 805B, 510 20th Street S, Birmingham, AL 35294, USA

${ }^{2}$ Department of Medicine at the School of Medicine and Division of Epidemiology at the School of Public Health, University of Alabama, Faculty Office Tower 805B, 510 20th Street S, Birmingham, AL 35294, USA Full list of author information is available at the end of the article
}

extremity osteoarthritis (OA), the most common reason for arthroplasty, has similar or higher prevalence in Blacks compared with Whites [8]. OA is more severe and more symptomatic in Blacks than Whites [9-13]. Arthroplasty, a definitive surgical treatment for end-stage OA (and other types of arthritis), is associated with significant improvements in quality of life and functional ability $[14,15]$; and there is no evidence that benefits of arthroplasty are lower in Blacks, compared with Whites. This implies that the need for arthroplasty is at least as great or greater in Blacks, when compared with Whites. Additionally, the benefits of arthroplasty do not seem to differ by race to justify a lower utilization in Blacks compared with Whites. However, numerous studies have shown that the utilization of knee or hip arthroplasty is much lower in Blacks than Whites [16-19]. This indicates that Blacks with end-stage arthritis are not experiencing the arthroplasty-associated quality-oflife improvements to the same extent as Whites. More

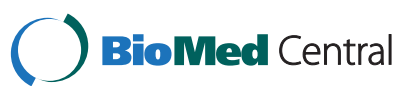

(c) 2015 Singh and Ramachandran.; licensee Biomed Central. This is an Open Access article distributed under the terms of the Creative Commons Attribution License (http://creativecommons.org/licenses/by/4.0), which permits unrestricted use, distribution, and reproduction in any medium, provided the original work is properly cited. The Creative Commons Public Domain Dedication waiver (http://creativecommons.org/publicdomain/zero/1.0/) applies to the data made available in this article, unless otherwise stated. 
studies are therefore needed to understand the extent and reasons for racial disparities in arthroplasty utilization.

Arthroplasty involves replacing diseased joint surfaces with plastic or metal components to relieve pain and improve joint function and mobility. Hip and knee joints are the most common lower extremity arthroplasty surgeries performed for end-stage arthritis. Another lower extremity joint affected not uncommonly is the ankle joint. Ankle joint arthritis can lead to disabling pain and functional limitation [20]. Total ankle arthroplasty (TAA) is the surgical treatment for end-stage ankle joint disease [21,22], an alternative to ankle arthrodesis [23]. The increasing use of TAA is due to much better clinical and radiographic outcomes with the second-generation and third-generation prostheses compared with the earlier designs [24,25].

In a recent study, we found an increase in TAA utilization in the United States from 1998 to 2011 [26]. As the utilization of TAA increases, an important question is whether the racial disparities described for knee and hip arthroplasty exist for TAA. To our knowledge, no studies have assessed racial disparities in TAA utilization and outcomes. Our study objectives were to assess racial disparities in TAA utilization and outcomes. We asked whether there are any racial disparities in utilization of TAA, whether utilization disparities between Blacks and Whites are decreasing over time, and whether the outcomes of TAA differ by race.

\section{Methods}

\section{Data source}

We used the National Inpatient Sample (NIS; previously called Nationwide Inpatient Sample) data from 1998 to 2011 for this study. The NIS is the largest inpatient care database that provides data on hospital inpatient stays for all patients in the United States, and is publicly available. The NIS contains data from approximately 8 million hospital stays each year. The US NIS contains approximately a $20 \%$ stratified sample of US community hospitals; in 2011, 46 states provided data [27]. The NIS includes all patients regardless of the payer. In other words, the NIS includes patients covered by Medicare, Medicaid, private insurance and the uninsured. Since the NIS has a representative sample, it has been used to analyze national trends in outcomes of various conditions during the inpatient stay [28,29]. The NIS can be weighted to obtain national estimates. The NIS contains primary and secondary diagnoses, patient demographics, length of stay, admission and discharge status, hospital characteristics and total charges. For each hospital admission, the International Classification of Diseases Ninth Revision Common Modification (ICD-9-CM) diagnostic and procedure information are available. The Institutional Review Board at the University of Alabama at Birmingham approved the study. No patient consent was needed, since these data are de-identified.
Study cohort, time periods, main predictor and covariates The study cohort consisted of patients who underwent a primary TAA, identified by the presence of ICD-9-CM procedure code 81.56 during the hospitalization, from 1998 to 2011. We divided the calendar years into 2-year to 3-year intervals a priori (1998 to 2000, 2001 to 2002, 2003 to 2004, 2005 to 2006, 2007 to 2008 and 2009 to 2011), in order to have an adequate number of cases for analyses for mortality, discharge status and length of hospital stay (since the groups with smaller numbers, Black males and Black females, had few or no patients with outcomes in some years).

Race, the main independent variable of interest, was categorized as White and Black. We included covariates previously shown or suspected to be associated with arthroplasty utilization and/or outcomes [30-35]. Patient demographic (age, sex) and clinical characteristics (underlying diagnosis, comorbidity) were obtained. We categorized age into $<50$ years, 50 to $<65$ years, 65 to $<80$ years and $\geq 80$ years, and the underlying diagnosis into OA, rheumatoid arthritis, avascular necrosis of the bone, fracture and other (post-traumatic arthritis, septic arthritis, Charcot joint, and so forth). Comorbidity was assessed using the validated Deyo-Charlson index [26], a sum of 17 comorbidities [27,28] at the index admission preoperatively, based on the presence of ICD-9-CM codes. The Deyo-Charlson index was categorized as 0,1 or 2 or more.

\section{Study outcomes}

The TAA utilization rates for Whites and Blacks were calculated by dividing the respective NIS estimates by the total US population for Whites/Blacks for the respective year obtained from the US census site, expressed per 100,000 patients [36]. Hospital length of stay was calculated as the number of days from admission to discharge for the index TAA admission. Mortality related to the index admission was assessed using the mortality during the index hospital admission. Discharge status was categorized as discharge: home with or without home health care; or to an inpatient facility that included a short-term hospital, a skilled nursing facility, an intermediate care facility or another type of inpatient facility. We excluded patients who died in the hospital or left the hospital against medical advice from the analyses of utilization and discharge outcomes only. Outcomes (hospital stay, discharge disposition and mortality) were calculated for categories of 2 or 3 years for time-trend analyses. We categorized the annual hospital volumes for TAA as $<5$ procedures/year, 5 to 9 procedures/year, 10 to 14 procedures/year, 15 to 24 procedures/year and $\geq 25$ procedures/year. Length of stay was categorized into greater than the median or less than the median. 


\section{Statistical analyses}

We calculated 95\% confidence intervals for utilization rates based on binomial proportions. We applied data weights as recommended to obtain weighted estimates [37]. We used the Cochran Armitage trend test to assess time trends from 1998 to 2011 and the chi-square test to compare TAA utilization between 1988 and 2011. Analysis of variance or the chi-squared test was used to compare the characteristics of Whites and Blacks undergoing TAA. Logistic regression was used to compare mortality, length of stay and discharge to home versus medical facility.

\section{Results}

\section{Patient characteristics}

In total, 12,122 Whites and 488 Blacks underwent TAA during the study period. The mean ages for the Whites and Blacks were 61.9 and 52.0 years, respectively; $55 \%$ and $62 \%$ were female, respectively (Table 1 ). The underlying diagnosis was $\mathrm{OA}$ in $62.5 \%$ of Whites and

Table 1 Characteristics of patients undergoing total ankle arthroplasty, 1998 to 2011

\begin{tabular}{|c|c|c|c|}
\hline & $\begin{array}{l}\text { White } \\
(n=12,122)\end{array}$ & $\begin{array}{l}\text { Black } \\
(n=488)\end{array}$ & $P$ value \\
\hline Age (years) & $61.9(61.1,62.7)$ & $52.0(49.6,54.3)$ & $<0.0001$ \\
\hline Female & 54.8 & 61.9 & 0.19 \\
\hline \multicolumn{4}{|l|}{ Age group } \\
\hline$<50$ years & 15.5 & 42.2 & $<0.0001$ \\
\hline 50 to 64 years & 38.3 & 43.6 & 0.28 \\
\hline 65 to 79 years & 41.2 & 12.5 & $<0.0001$ \\
\hline$\geq 80$ years & 5.1 & 1.7 & 0.11 \\
\hline \multicolumn{4}{|l|}{ Underlying diagnosis } \\
\hline Osteoarthritis & 62.5 & 47.2 & 0.005 \\
\hline Rheumatoid arthritis & 5.6 & 10.3 & 0.04 \\
\hline Fracture & 0.1 & 1.0 & 0.04 \\
\hline Traumatic arthropathy & 18.8 & 18.6 & 0.96 \\
\hline Avascular necrosis & 0.5 & 0.9 & 0.51 \\
\hline Other & 12.6 & 22.0 & 0.01 \\
\hline \multicolumn{4}{|l|}{ Deyo-Charlson score } \\
\hline 0 & 71.8 & 65.8 & 0.25 \\
\hline 1 & 23.2 & 22.9 & 0.96 \\
\hline$\geq 2$ & 5.0 & 11.2 & 0.01 \\
\hline \multicolumn{4}{|l|}{$\begin{array}{l}\text { Hospital volume } \\
\text { (procedures/year) }\end{array}$} \\
\hline$<5$ & 35.2 & 47.6 & 0.04 \\
\hline 5 to 9 & 25.6 & 26.5 & 0.89 \\
\hline 10 to 14 & 12.3 & 5.7 & 0.14 \\
\hline 15 to 24 & 17.7 & 14.4 & 0.42 \\
\hline$\geq 25$ & 9.3 & 5.8 & 0.21 \\
\hline
\end{tabular}

Data presented as mean (95\% confidence interval) or percentage.
$47.2 \%$ of Blacks. A total $5 \%$ of Whites and $11.2 \%$ of Blacks had a Deyo-Charlson index $\geq 2$ (Table 1). A significantly higher proportion of Blacks (47.6\%) than Whites $(35.2 \% ; P=0.04)$ underwent TAA at a hospital with an annual volume $<5$ TAA procedures (Table 1 ).

\section{Time trends in TAA utilization by race}

We compared the time trends in TAA utilization by race. TAA utilization was significantly higher in Whites than Blacks in 1998, 0.14 versus 0.07 per $100,000(P<0.0001$; twofold rate) (Table 2 and Figure 1). In 2011, TAA utilization was 1.17 in Whites and 0.33 in Blacks, showing significant racial disparities $(P<0.0001 ; 3.5$-fold rate). Disparities in TAA utilization by race increased statistically significantly from 1998 to 2011 ( $P<0.0001)$. The twofold higher rate in Whites compared with Blacks in 1998 increased to an almost fourfold higher rate in 2011 (Table 2 and Figure 1). The absolute White-Black difference in TAA utilization rate was 0.07 per 100,000 in 1998 and 0.84 per 100,000 in 2011 (a 12-fold higher difference).

In further analyses of Whites and Blacks by sex, we found that the utilization rates differed significantly between the groups in 1998 and 2011, numerically slightly higher in females than males (Table 3). In addition, the rates increased significantly from 1998 to 2011 in White males $(P<0.0001)$, White females $(P<0.0001)$, Black males $(P=0.0031)$ and Black females $(P<0.0001)$.

A significant increase in TAA utilization over time (1998 to 2011) was seen for all four age groups in

Table 2 Time trends in annual total ankle arthroplasty utilization by race

\begin{tabular}{llll}
\hline Year & White & Black & $P$ value \\
\hline 1998 & 0.14 & 0.07 & $<0.0001$ \\
1999 & 0.32 & 0.04 & $<0.0001$ \\
2000 & 0.29 & 0.07 & $<0.0001$ \\
2001 & 0.52 & 0.01 & $<0.0001$ \\
2002 & 0.35 & 0.13 & $<0.0001$ \\
2003 & 0.33 & 0.08 & $<0.0001$ \\
2004 & 0.40 & 0.06 & $<0.0001$ \\
2005 & 0.25 & 0.07 & $<0.0001$ \\
2006 & 0.18 & 0.05 & $<0.0001$ \\
2007 & 0.26 & 0.05 & $<0.0001$ \\
2008 & 0.47 & 0.10 & $<0.0001$ \\
2009 & 0.58 & 0.18 & $<0.0001$ \\
2010 & 0.90 & 0.09 & $<0.0001$ \\
2011 & 1.17 & 0.33 & $<0.0001$ \\
\hline
\end{tabular}

Total ankle arthroplasty utilization rates increased from 1998 to 2011: White, $P<0.0001$; Black, $P<0.0001$ (Cochran Armitage trend test for time trends). White-Black disparity was significantly more in 2011 compared with 1998: $P<0.0001$. 


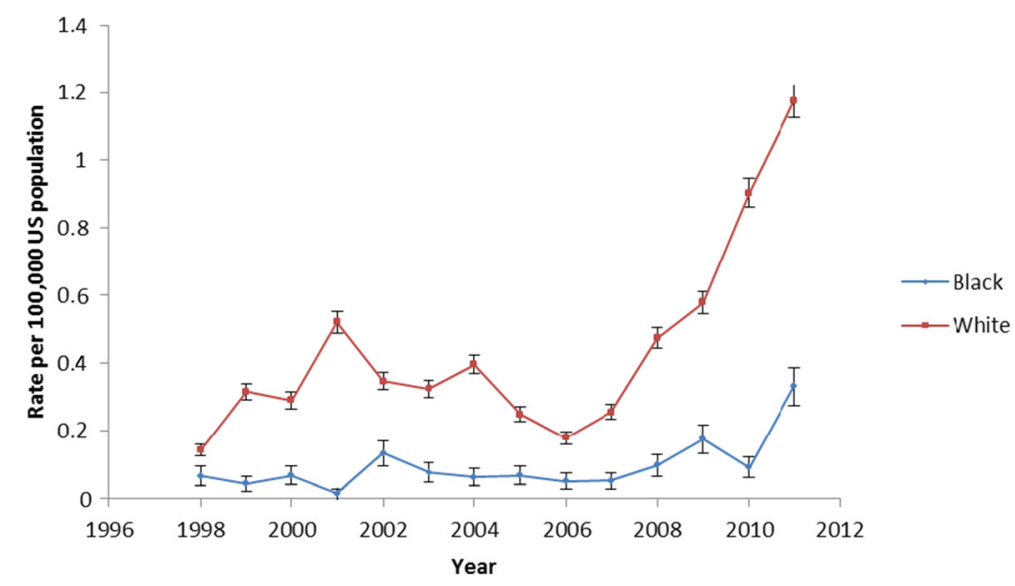

Figure 1 Total ankle arthroplasty utilization rates per 100,000 in Whites and Blacks over time.

Whites except for $<50$ years $(P=0.11$ for $<50$ years and $P<0.0001$ for all others; Figure 2). When comparing 1998 with 2011, TAA utilization increased significantly for all age groups $(P<0.0001)$. In Blacks, no significant time-related increase in TAA utilization rates was seen in the $<50$ or 50 to 64 age categories $(P=0.07$ and $0.053)$ and slight increases in the 65 to 79 and $\geq 80$ age groups $(P=0.009$ and 0.0002 ; Figure 2$)$. Additional file 1 shows these time trends in utilization by race in more detail. Over time, we noted an increase in age and comorbidity, and change in the underlying diagnosis.

\section{Outcomes variation by race}

The proportion of Black patients with hospital stay longer than the median stay was higher than White patients $(52.9 \%$ vs. $44.3 \%)$, with a trend towards significance $(P=0.08$; Table 4$)$. A slightly higher proportion of Blacks compared with Whites were discharged to an inpatient facility after TAA (16.6\% vs. $13.4 \%)$, but this was not significant $(P=0.36)$. Five Whites and four Blacks died after TAA; mortality was higher in Blacks compared with Whites $(P=0.02$; Table 4$)$. Additional file 2 shows these outcomes by time period in more detail. In general, the length of stay decreased and discharge to an inpatient facility increased over time.

\section{Discussion}

To our knowledge, our study is the first to examine racial disparities in TAA utilization and outcomes in the United States. We found important differences in

Table 3 Time trends in total ankle arthroplasty utilization rates per 100,000 by race and gender

\begin{tabular}{|c|c|c|c|c|c|}
\hline & White males & Black males & White females & Black females & $P$ value \\
\hline 1998 & 0.11 & 0.07 & 0.17 & 0.06 & $<0.0001$ \\
\hline 1999 & 0.36 & 0.09 & 0.27 & 0 & N/A \\
\hline 2000 & 0.29 & 0 & 0.29 & 0.13 & N/A \\
\hline 2001 & 0.49 & 0 & 0.56 & 0.03 & N/A \\
\hline 2002 & 0.28 & 0.06 & 0.41 & 0.20 & $<0.0001$ \\
\hline 2003 & 0.25 & 0.11 & 0.39 & 0.05 & $<0.0001$ \\
\hline 2004 & 0.34 & 0.03 & 0.45 & 0.10 & $<0.0001$ \\
\hline 2005 & 0.22 & 0.03 & 0.28 & 0.10 & $<0.0001$ \\
\hline 2006 & 0.16 & 0.11 & 0.19 & 0 & N/A \\
\hline 2007 & 0.22 & 0.04 & 0.29 & 0.06 & $<0.0001$ \\
\hline 2008 & 0.42 & 0.05 & 0.53 & 0.14 & $<0.0001$ \\
\hline 2009 & 0.57 & 0.19 & 0.59 & 0.16 & $<0.0001$ \\
\hline 2010 & 0.84 & 0.05 & 0.97 & 0.12 & $<0.0001$ \\
\hline 2011 & 1.13 & 0.25 & 1.22 & 0.41 & $<0.0001$ \\
\hline
\end{tabular}

$\mathrm{N} / \mathrm{A}$, not applicable since a frequency of 0 for at least one category did not allow calculation of a $P$ value; a frequency of 0 indicates that no TAA procedure was performed in that group in that calendar year. Cochran Armitage trend test for time trend from 1998 to 2011: White males, $P<0.0001$; Black males, $P=0.0031$; White females, $P<0.0001$; and Black females, $P<0.0001$. The $\mathrm{p}$-value in the table indicates the difference between the groups. 

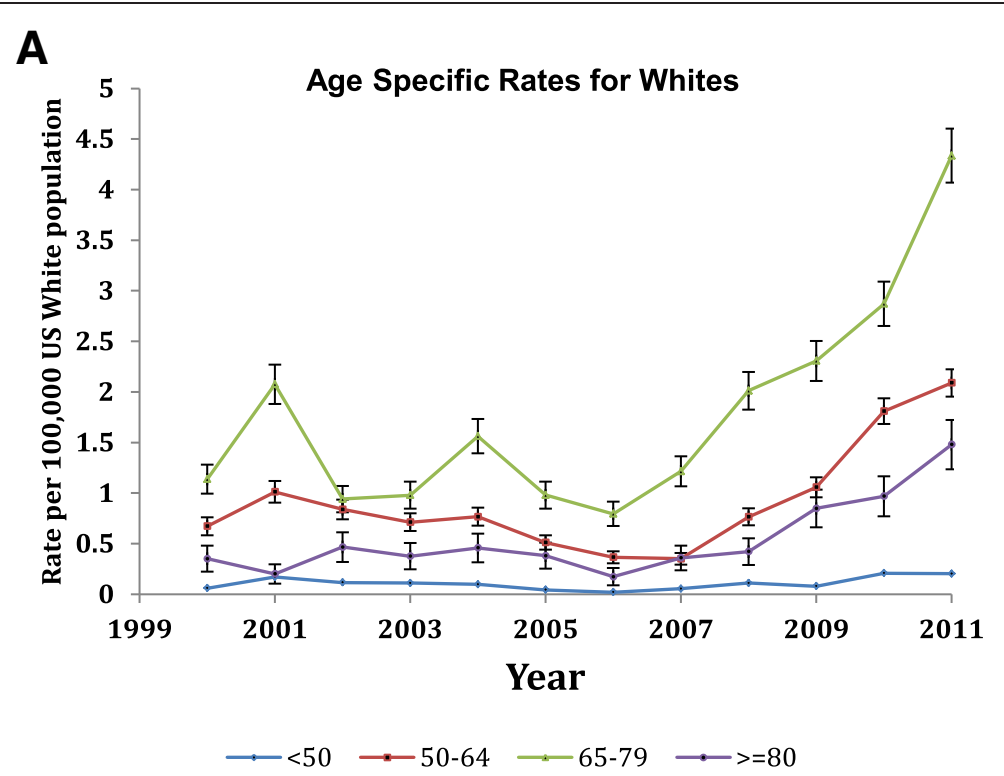

B

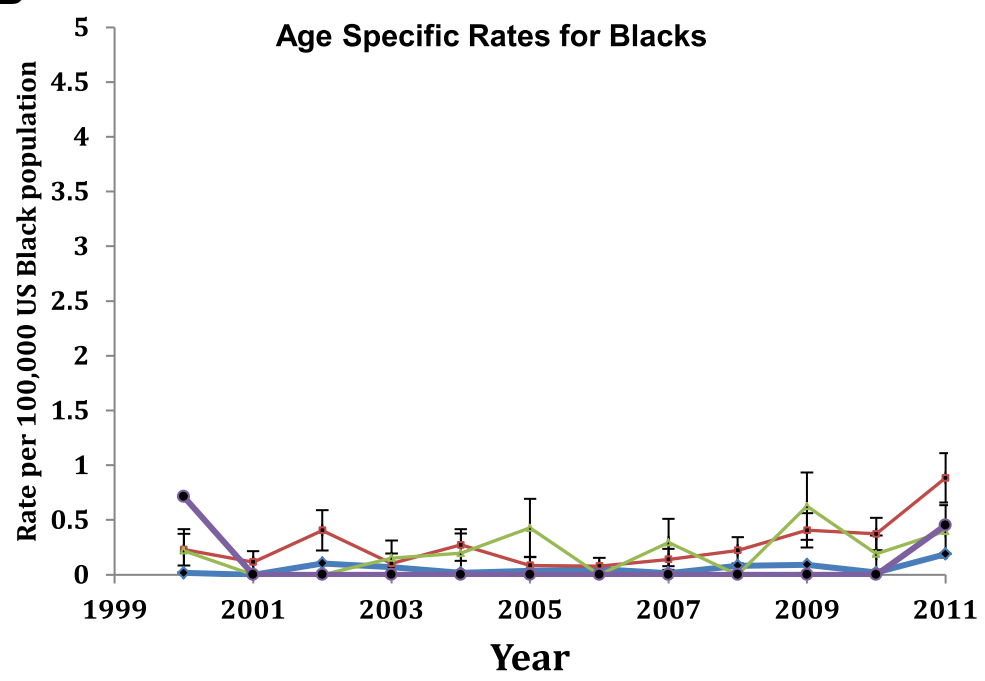

$\rightarrow<50 \rightarrow-50-64 \longrightarrow 65-79 \rightarrow>=80$

Figure 2 Age-specific total ankle arthroplasty utilization rates per 100,000 for Whites and Blacks. (A) Age-specific rates for Whites. Cochran Armitage test comparing total ankle arthroplasty (TAA) utilization in all years: age $<50, P=0.11$; age 50 to $64, P<0.0001$; age 65 to 79 , $P<0.0001$; age $\geq 80, P<0.0001$. (B) Age-specific rates for Blacks. Cochran Armitage test comparing TAA utilization in all years: age $<50, P=0.07$; age 50 to $64, P=0.053$; age 65 to $79, P=0.009$; age $\geq 80, P=0.0002$.

Table 4 Unadjusted outcomes by race including all data from 1998 to 2011

\begin{tabular}{lllc}
\hline & White $(\boldsymbol{n}=\mathbf{1 2 , 1 2 2})$ & Black $(\boldsymbol{n}=\mathbf{4 8 8})$ & $\boldsymbol{P}$ value \\
\hline $\begin{array}{l}\text { Length of stay }>\text { median } \\
\text { Discharge }\end{array}$ & $5,366(44.3 \%)$ & $258(52.9 \%)$ & 0.08 \\
$\quad$ Home & $10,476(86.6 \%)$ & $403(83.4 \%)$ & 0.36 \\
Inpatient facility & $1,628(13.4 \%)$ & $80(16.6 \%)$ & \\
$\quad$ Mortality & $5(0.04 \%)$ & $4(0.9 \%)$ & 0.02 \\
\hline
\end{tabular}

Data presented as $n(\%)$. demographic and clinical characteristics of Blacks and Whites undergoing TAA. The TAA utilization rates were lower in Blacks compared with Whites for all years. White-Black disparities in TAA utilization increased over the 12-year period, from a twofold higher rate in Whites compared with Blacks in 1998 to an almost fourfold higher rate in 2011, significant both statistically and clinically (absolute difference in rate increased 12-fold). Blacks had a longer hospital stay and higher mortality compared with Whites, but no differences in discharge 
to home versus an inpatient facility. Several findings from our study merit further discussion.

The TAA utilization rate was significantly lower in Blacks compared with Whites in 1998 as well as 2011. The absolute White-Black difference in TAA utilization rate was 0.07 per 100,000 in 1998 and 0.84 per 100,000 in 2011 (a 12-fold higher difference) and the relative rate was twofold in 1998 and fourfold in 2011. Racial disparities increased significantly, both statistically and in a clinical meaningful way. Our time-trend analysis is the first to indicate that there was clear evidence of widening racial disparity in TAA utilization over the 12-year study period. Racial disparities with lower rates of knee and hip arthroplasty utilization in Blacks, compared with Whites, have been shown in studies using regional data [38] and national Medicare data [18]. Our study extended these findings of the presence of racial disparities to TAA populations. The increasing disparities in TAA utilization should be very concerning, since this trend was far worse than an absence of reduction of disparities in the utilization over time for knee/hip arthroplasty, reported previously $[39,40]$. Policy-makers should consider the worsening racial disparities in TAA utilization rates an important warning. This trend of worsening disparities is in the opposite direction to that recommended by the 2012 Institute of Medicine report [6], which drew attention to existing racial disparities in health care and the need to reduce and eliminate disparities. We found an increasing gap in TAA utilization between Blacks and Whites over time. Our study findings of increasing disparity indicate that policy-makers need to develop and implement policies to eliminate these disparities, including the widening gap in TAA utilization between Blacks and Whites.

The lower arthroplasty utilization rates in Blacks could not be explained by surgical appropriateness or disease burden, since there are no significant racial differences in proportions with at least moderately severe OA deemed appropriate for arthroplasty [41]. Blacks have a higher disease burden of arthritis than Whites [8-13]. Socioeconomic status differences explained only some racial differences in arthroplasty utilization [42]. Blacks have a higher fear of arthroplasty compared with Whites [43]. Previous studies showed that Blacks presented with worse preoperative hip and knee function at the time of hip or knee arthroplasty than Whites [44] and had longer delays to presentation and higher body mass index at the time of hip arthroplasty compared with Whites [45]. This indicated a worse preoperative patient status in Blacks undergoing arthroplasty, which is associated with poorer postoperative pain and function outcomes [46]. Blacks were less willing than Whites to undergo total knee or hip joint replacement surgery [47]. Future studies are needed to explore whether patient preferences, health care access barriers, adequacy of social support/network and/ or other factors can explain these racial disparities. A better understanding of racial disparities and factors associated with it will help the development of interventions targeting these racial disparities in arthroplasty utilization. With our findings in TAA, these findings may be particularly relevant to Blacks undergoing TAA. Once effective interventions can be developed, they can be implemented to eliminate these racial disparities.

We found that Blacks undergoing TAA differed from Whites regarding demographic and clinical characteristics. Blacks undergoing TAA were younger than Whites, had a higher proportion of females, had differences in the underlying diagnosis (lower proportion had OA, higher proportion had rheumatoid arthritis and other diagnoses) and had higher comorbidity. Since the impact of each of these characteristics (age, sex, diagnosis and medical comorbidity) on TAA outcomes is not known at this time, it is not possible to predict whether these factors positively or negatively impact the outcomes of TAA in Blacks versus Whites. Future studies that can examine the impact of these factors on outcomes can help us better understand their contribution to differences in TAA outcomes or the lack thereof.

We found that a higher proportion of Blacks who underwent TAA had hospital stay longer than the overall median hospital stay compared with Whites, which almost reached significance $(P=0.056)$. Mortality after TAA, although rare in both Blacks and Whites, was higher in Blacks compared with Whites. These are novel findings. In the absence of any previous studies, no comparisons could be made. This longer hospital stay in Blacks compared with Whites might be due to a delayed presentation [45], worse preoperative pain and function [44], and worse function on performance tests [13] in Blacks, all of which can delay post-arthroplasty recovery.

Our study showed that Blacks were also more likely to undergo TAA at hospitals with the lowest annual volume ( $<5$ procedures/year) compared with Whites. This racial difference in utilization of hospitals with lower volume may have contributed to worse outcomes among Blacks compared with Whites after TAA, including a longer post-arthroplasty hospital stay and higher mortality in Blacks. Racial differences in social support, higher comorbidity and higher rates of other risk factors for poor outcomes and mortality might also have contributed. This finding is similar to a recent finding by Cai and colleagues that Blacks undergoing knee/hip arthroplasty were more likely than Whites to be admitted to hospitals with higher risk-adjusted postoperative rates of complications or mortality [48]. Studies need to explore why minorities are more likely to undergo arthroplasty at low-volume hospitals, which are often associated with worse outcomes. The practical implications of these findings are that Blacks 
need education resources to become knowledgeable regarding the association of hospital volume and arthroplasty outcomes to make informed decisions.

Our study findings must be interpreted considering the study limitations and strengths. The NIS treats each hospital admission as an event, which would theoretically miss bilateral TAAs performed during a single hospitalization. Bilateral TAA is rare, however, so this is unlikely to have biased the estimates. The NIS does not include federal facilities such as military and Veterans Affairs hospitals. However, it is a nationally representative dataset and several studies using NIS data for knee, shoulder and hip arthroplasty have been published [49-52], supporting its generalizability. We used the entire US population for calculating the rates, a method that has been used in other studies from the NIS [53,54]. We used the ICD-9-CM for identifying TAA, similar to the codes used in other arthroplasty studies, which have been found to be accurate [55]. Another limitation of these analyses is that the underlying diagnoses of OA/ rheumatoid arthritis/avascular necrosis and so forth may or may not be joint specific; their accuracy and positive predictive values have not been established and therefore some misclassification is possible. Mortality differences were based on very small numbers and therefore should be interpreted with caution.

\section{Conclusions}

This study found that the racial disparity in annual TAA utilization increased from twofold in 1998 to fourfold in 2011 in the United States. Blacks also had a slightly longer hospital stay and higher mortality compared with Whites. There were no racial differences in discharge disposition. The persisting and perhaps worsening racial disparities in TAA utilization and outcomes over a 13year study period should serve as a wake-up call for patients, surgeons and policy-makers. Further studies are needed to investigate why the racial disparities in TAA are worsening and to develop strategies for addressing this problem. Policy-makers should implement policies that can reduce this racial disparity gap in utilization and outcomes of TAA.

\section{Additional files}

Additional file 1: Is a table presenting the characteristics of patients undergoing TAA by race across years in the study period. Comparisons of TAA utilization in Whites and Blacks over the study period from 1998 to 2010 and change in Whites and Blacks from the first (1998 to 2000) to the last (2009 to 2010) study period.

Additional file 2: Is a table presenting TAA outcomes by race from 1998 to 2010. Comparisons of outcomes (mortality, discharge disposition and length of hospital stay) after TAA in Whites and Blacks over the study period from 1998 to 2010 and the change in Whites and Blacks from the first (1998 to 2000) to the last (2009 to 2010) study period.

\section{Abbreviations}

ICD-9-CM: International Classification of Diseases Ninth Revision Common Modification; NIS: National Inpatient Sample; OA: osteoarthritis; TAA: total ankle arthroplasty.

\section{Competing interests}

The authors declare that they have no financial or nonfinancial competing interests related directly to this study. JAS has received research and travel grants from Takeda and Savient; and consultant fees from Savient, Takeda, Allergan and Regeneron. RR declares that he has no competing interests.

\section{Authors' contributions}

JAS was responsible for conception of the study, development of study protocol and methods, data acquisition and analyses, review and interpretation of data, writing the first draft, revision of the manuscript, the decision to submit and approval of the final version of the manuscript. RR was responsible for development of the study protocol and methods, data acquisition and analyses, review and interpretation of data, revision of the manuscript, the decision to submit and approval of the final version of the manuscript.

\section{Acknowledgements}

This material is the result of work supported by the resources and use of facilities at the Birmingham VA Medical Center, AL, USA. JAS is also supported by grants from the Agency for Health Quality and Research Center for Education and Research on Therapeutics (CERTs), the National Institute of Arthritis, Musculoskeletal and Skin Diseases (NIAMS), the National Institute of Aging and the National Cancer Institute.

\section{Author details}

${ }^{1}$ Medicine Service, Birmingham VA Medical Center, Faculty Office Tower 805B, 510 20th Street S, Birmingham, AL 35294, USA. ²Department of Medicine at the School of Medicine and Division of Epidemiology at the School of Public Health, University of Alabama, Faculty Office Tower 805B, 510 20th Street S, Birmingham, AL 35294, USA. ${ }^{3}$ Department of Orthopedic Surgery, Mayo Clinic College of Medicine, 200 1st St SW, Rochester, MN 55905, USA.

Received: 31 May 2014 Accepted: 25 February 2015

Published online: 21 March 2015

\section{References}

1. Hayanga AJ. Risk of pancreatic adenocarcinoma: disparity between African Americans and other race/ethnic groups. Cancer. 2005;104:2530-1. author reply 2531.

2. Kimball MM, Neal D, Waters MF, Hoh BL. Race and income disparity in ischemic stroke care: nationwide inpatient sample database, 2002 to 2008. J Stroke Cerebrovasc Dis. 2014;23:17-24.

3. Kreatsoulas C, Anand SS. Disparity in outcomes of surgical revascularization for limb salvage. Race and gender are synergistic determinants of vein graft failure and limb loss. Nguyen LL, Hevelone N, Rogers SO, Bandyk DF, Clowes AW, Moneta GL, Lipsitz S, Conte MS. Circulation. 2009:119:123-30. Vasc Med. 2009:14:397-9.

4. Sclar DA, Robison LM, Schmidt JM, Bowen KA, Castillo LV, Oganov AM. Diagnosis of depression and use of antidepressant pharmacotherapy among adults in the United States: does a disparity persist by ethnicity/ race? Clin Drug Investig. 2012;32:139-44.

5. Wellons MF, Fujimoto VY, Baker VL, Barrington DS, Broomfield D, Catherino $\mathrm{WH}$, et al. Race matters: a systematic review of racial/ethnic disparity in Society for Assisted Reproductive Technology reported outcomes. Fertil Steril. 2012;98:406-9.

6. Committee on Understanding and Eliminating Racial and Ethnic Disparities in Health Care. Unequal treatment: confronting racial and ethnic disparities in health care. Full printed version. 2003. http://www.nap.edu/catalog/ 10260.html. Accessed 30 March 2015.

7. Institute of Medicine. 100 initial priority topics for comparative effectiveness research. http://www.iom.edu/ /media/Files/Report\%20Files/2009/Comparative EffectivenessResearchPriorities/Stand\%20Alone\%20List\%20of\%20100\%20CER\% 20Priorities\%20-\%20for\%20web.ashxttr. Accessed 30 March 2015.

8. Nelson AE, Renner JB, Schwartz TA, Kraus VB, Helmick CG, Jordan JM. Differences in multijoint radiographic osteoarthritis phenotypes among 
African Americans and Caucasians: the Johnston County Osteoarthritis project. Arthritis Rheum. 2011;63:3843-52.

9. Braga L, Renner JB, Schwartz TA, Woodard J, Helmick CG, Hochberg MC, et al. Differences in radiographic features of knee osteoarthritis in AfricanAmericans and Caucasians: the Johnston county osteoarthritis project. Osteoarthritis Cartilage. 2009;17:1554-61.

10. Allen KD, Chen JC, Callahan LF, Golightly YM, Helmick CG, Renner JB, et al. Racial differences in knee osteoarthritis pain: potential contribution of occupational and household tasks. J Rheumatol. 2012;39:337-44.

11. Allen KD. Racial and ethnic disparities in osteoarthritis phenotypes. Curr Opin Rheumatol. 2010;22:528-32.

12. Allen KD, Oddone EZ, Coffman CJ, Keefe FJ, Lindquist JH, Bosworth HB. Racial differences in osteoarthritis pain and function: potential explanatory factors. Osteoarthritis Cartilage. 2010;18:160-7.

13. Burns R, Graney MJ, Lummus AC, Nichols LO, Martindale-Adams J. Differences of self-reported osteoarthritis disability and race. J Natl Med Assoc. 2007;99:1046-51.

14. Jones CA, Pohar S. Health-related quality of life after total joint arthroplasty: a scoping review. Clin Geriatr Med. 2012;28:395-429.

15. Ethgen O, Bruyere O, Richy F, Dardennes C, Reginster JY. Health-related quality of life in total hip and total knee arthroplasty. A qualitative and systematic review of the literature. J Bone Joint Surg Am. 2004;86-A:963-74.

16. Ibrahim SA, Siminoff LA, Burant CJ, Kwoh CK. Understanding ethnic differences in the utilization of joint replacement for osteoarthritis: the role of patient-level factors. Med Care. 2002;40:144-51.

17. Ibrahim SA, Stone RA, Han X, Cohen P, Fine MJ, Henderson WG, et al. Racial/ethnic differences in surgical outcomes in veterans following knee or hip arthroplasty. Arthritis Rheum. 2005;52:3143-51.

18. Skinner J, Weinstein JN, Sporer SM, Wennberg JE. Racial, ethnic, and geographic disparities in rates of knee arthroplasty among Medicare patients. N Engl J Med. 2003;349:1350-9.

19. Singh JA, Lu X, Rosenthal GE, Ibrahim S, Cram P. Racial disparities in knee and hip total joint arthroplasty: an 18-year analysis of national medicare data. Ann Rheum Dis. 2014;73:2107-15.

20. Agel J, Coetzee JC, Sangeorzan BJ, Roberts MM, Hansen Jr ST. Functional limitations of patients with end-stage ankle arthrosis. Foot Ankle Int. 2005;26:537-9.

21. Wood PL, Clough TM, Smith R. The present state of ankle arthroplasty. Foot Ankle Surg. 2008;14:115-9.

22. Park JS, Mroczek KJ. Total ankle arthroplasty. Bull NYU Hosp Jt Dis. 2011;69:27-35.

23. Coester LM, Saltzman CL, Leupold J, Pontarelli W. Long-term results following ankle arthrodesis for post-traumatic arthritis. J Bone Joint Surg Am. 2001;83-A:219-28.

24. Queen RM, De Biassio JC, Butler RJ, DeOrio JK, Easley ME, Nunley JA. J. Leonard Goldner Award 2011: changes in pain, function, and gait mechanics two years following total ankle arthroplasty performed with two modern fixed-bearing prostheses. Foot Ankle Int. 2012;33:535-42.

25. Sproule JA, Chin T, Amin A, Daniels T, Younger AS, Boyd G, et al. Clinical and radiographic outcomes of the mobility total ankle arthroplasty system: early results from a prospective multicenter study. Foot Ankle Int. 2013:34:491-7.

26. Singh JA, Ramachandaran R. Time trends in total ankle arthroplasty in the U.S.: a study of the Nationwide Inpatient Sample. Clin Rheumatol. 2014 Jun 7. [Epub ahead of print] PMID: 24907036

27. Healthcare Cost and Utilization Project. Overview of the Nationwide Inpatient Sample (NIS). http://www.hcup-us.ahrq.gov/nisoverview.jsp. Accessed 30 March 2015.

28. Masoomi H, Mills S, Dolich MO, Ketana N, Carmichael JC, Nguyen NT, et al. Comparison of outcomes of laparoscopic versus open appendectomy in children: data from the Nationwide Inpatient Sample (NIS), 2006-2008. World J Surg. 2012;36:573-8.

29. Shivaraju A, Patel V, Fonarow GC, Xie H, Shroff AR, Vidovich MI. Temporal trends in gastrointestinal bleeding associated with percutaneous coronary intervention: analysis of the 1998-2006 Nationwide Inpatient Sample (NIS) database. Am Heart J. 2011;162:1062-8. e1065.

30. Singh JA, Lewallen D. Age, gender, obesity, and depression are associated with patient-related pain and function outcome after revision total hip arthroplasty. Clin Rheumatol. 2009:28:1419-30.

31. Singh JA, Lewallen DG. Medical comorbidity is associated with persistent index hip pain after total hip arthroplasty. Pain Med. 2013;14:1222-9.
32. Singh JA, Jensen MR, Harmsen SW, Lewallen DG. Are gender, comorbidity, and obesity risk factors for postoperative periprosthetic fractures after primary total hip arthroplasty? J Arthroplasty. 2013;28:126-31. e121-2.

33. Singh JA, Lewallen DG. Underlying diagnosis predicts patient-reported outcomes after revision total knee arthroplasty. Rheumatology (Oxford). 2014;53:361-6.

34. Singh JA, Lewallen DG. Operative diagnosis for revision total hip arthroplasty is associated with patient-reported outcomes (PROs). BMC Musculoskelet Disord. 2013;14:210.

35. Singh JA, Vessely MB, Harmsen WS, Schleck CD, Melton 3rd LJ, Kurland RL, et al. A population-based study of trends in the use of total hip and total knee arthroplasty, 1969-2008. Mayo Clin Proc. 2010;85:898-904.

36. United States Census Bureau. The 2012 statistical abstract. Population. http://www.census.gov/compendia/statab/cats/population.html. Accessed 30 March 2015.

37. HCUP methods series calculating Nationwide Inpatient Sample variances. Report \#2003-2. http://www.hcup-us.ahrq.gov/reports/methods/2003_02.jsp. Accessed 30 March 2015.

38. Hoaglund FT, Oishi CS, Gialamas GG. Extreme variations in racial rates of total hip arthroplasty for primary coxarthrosis: a population-based study in San Francisco. Ann Rheum Dis. 1995;54:107-10.

39. Jha AK, Fisher ES, Li Z, Orav EJ, Epstein AM. Racial trends in the use of major procedures among the elderly. N Engl J Med. 2005;353:683-91.

40. Singh JA, Lewallen DG. Time trends in the characteristics of patients undergoing primary total knee arthroplasty. Arthritis Care Res (Hoboken). 2014;66:897-906.

41. Ang DC, James G, Stump TE. Clinical appropriateness and not race predicted referral for joint arthroplasty. Arthritis Rheum. 2009;61:1677-85.

42. Skinner J, Zhou W, Weinstein J. The influence of income and race on total knee arthroplasty in the United States. J Bone Joint Surg Am. 2006;88:2159-66.

43. Lavernia CJ, Alcerro JC, Rossi MD. Fear in arthroplasty surgery: the role of race. Clin Orthop Relat Res. 2010;468:547-54

44. Slover JD, Walsh MG, Zuckerman JD. Sex and race characteristics in patients undergoing hip and knee arthroplasty in an urban setting. J Arthroplasty. 2010;25:576-80.

45. Kamath AF, Horneff JG, Gaffney V, Israelite CL, Nelson CL. Ethnic and gender differences in the functional disparities after primary total knee arthroplasty. Clin Orthop Relat Res. 2010;468:3355-61.

46. Singh JA, Gabriel S, Lewallen D. The impact of gender, age, and preoperative pain severity on pain after TKA. Clin Orthop Relat Res. 2008;466:2717-23.

47. Allen KD, Golightly YM, Callahan LF, Helmick CG, Ibrahim SA, Kwoh CK, et al. Race and sex differences in willingness to undergo total joint replacement: the johnston county osteoarthritis project. Arthritis Care Res (Hoboken). 2014:66:1193-202.

48. Cai X, Cram P, Vaughan-Sarrazin M. Are African American patients more likely to receive a total knee arthroplasty in a low-quality hospital? Clin Orthop Relat Res. 2012;470:1185-93.

49. Kurtz S, Mowat F, Ong K, Chan N, Lau E, Halpern M. Prevalence of primary and revision total hip and knee arthroplasty in the United States from 1990 through 2002. J Bone Joint Surg Am. 2005;87:1487-97.

50. Jain N, Pietrobon R, Hocker S, Guller U, Shankar A, Higgins LD. The relationship between surgeon and hospital volume and outcomes for shoulder arthroplasty. J Bone Joint Surg Am. 2004;86-A:496-505.

51. Kim SH, Wise BL, Zhang Y, Szabo RM. Increasing incidence of shoulder arthroplasty in the United States. J Bone Joint Surg Am. 2011;93:2249-54.

52. Kurtz S, Ong K, Lau E, Mowat F, Halpern M. Projections of primary and revision hip and knee arthroplasty in the United States from 2005 to 2030. J Bone Joint Surg Am. 2007;89:780-5.

53. Jain NB, Higgins LD, Guller U, Pietrobon R, Katz JN. Trends in the epidemiology of total shoulder arthroplasty in the United States from 1990-2000. Arthritis Rheum. 2006;55:591-7.

54. Jain NB, Higgins LD, Ozumba D, Guller U, Cronin M, Pietrobon R, et al. Trends in epidemiology of knee arthroplasty in the United States, 1990-2000. Arthritis Rheum. 2005;52:3928-33.

55. Katz JN, Losina E, Barrett J, Phillips CB, Mahomed NN, Lew RA, et al. Association between hospital and surgeon procedure volume and outcomes of total hip replacement in the United States medicare population. J Bone Joint Surg Am. 2001;83-A:1622-9. 